\title{
What will be the role of I-123 MIBG in improving the outcome of medically treated heart failure patients?
}

\author{
Fahad Waqar, MD, Stephanie H. Dunlap, DO, and Myron C. Gerson, MD,
}

Heart failure (HF) remains the most common cause for hospital admissions in the Medicare age population. ${ }^{1}$ In recent decades, major advances in medical treatment of $\mathrm{HF}$ patients have resulted in longer survival and improved quality of life. Randomized clinical trials have documented that beta-adrenergic blockers ( $\beta$-blockers), angiotensin-converting enzyme inhibitors (ACE-inhibitors), angiotensin receptor blockers (ARBs), and aldosterone inhibitors have provided improved outcomes for HF patients. Although widely used, these medications have frequently not been used in the doses validated in large clinical trials. This likely reflects concerns about using the full doses of $\beta$-blockers in patients with baseline bradycardia and/or using increasing doses of $\beta$-blockers, ACE-inhibitors, or ARBs in patients with low baseline systolic blood pressure. Maximum benefit of pharmacologic therapy is limited by inadequate data for drug selection for individual HF patients and inadequate data documenting the optimal therapeutic target for blood pressure and heart rate.

Excessive activity of the sympathetic nervous system is a major contributor to HF progression, by increasing cardiac work, promoting myocardial fibrosis, and causing down-regulation of post-synaptic adrenergic receptors. ${ }^{2}$ The impact of the sympathetic nervous system in HF patients can be assessed non-invasively by imaging cardiac neuronal uptake and retention of the norepinephrine congener, I-123 metaiodobenzylguanidine (I-123 MIBG). A growing literature addresses the

From the Division of Cardiovascular Diseases, Department of Internal Medicine, University of Cincinnati College of Medicine, Cincinnati, $\mathrm{OH}$.

This study is funded in part by the John R. Strauss Fund for Research and Education in Cardiac Imaging, Cincinnati, Ohio.

Reprint requests: Myron C. Gerson, MD, Division of Cardiovascular Diseases, Department of Internal Medicine, University of Cincinnati College of Medicine, P.O. Box 670542, Cincinnati, OH 45267-0542; myron.gerson@uc.edu.

J Nucl Cardiol 2012;19:1198-205.

$1071-3581 / \$ 34.00$

Copyright (c) 2012 American Society of Nuclear Cardiology.

doi:10.1007/s12350-012-9612-z potential role of I-123 MIBG for identifying HF patients at high risk for sudden cardiac death, in whom implantation of a cardioverter-defibrillator may be life-saving. ${ }^{3}$ Relatively little attention has been focused on the potential role of I-123 MIBG in guiding medical therapy of HF and avoidance of HF progression. Therefore, this review focuses on the question of whether sympathetic cardiac neural imaging with I-123 MIBG has the potential to guide medical therapy of properly selected patients with advanced HF, thereby improving symptoms and outcome.

\section{TARGET DOSES OF $\boldsymbol{\beta}$-BLOCKERS}

Treatment with $\beta$-blockers has been shown to reduce cardiac work, up-regulate post-synaptic adrenergic receptors, ${ }^{4}$ and with carvedilol, for example, reduce proliferation, possibly through antioxidant properties. $^{5}$ $\beta$-blockers reduce the risk of death in patients with chronic HF (CHF). ${ }^{6-9}$ They are a mainstay of HF management for patients with stages $\mathrm{B}, \mathrm{C}$, or D HF. According to the ACC/AHA 2005 guideline update for the diagnosis and management of chronic HF, there are few contraindications to their use. ${ }^{10}$ More than 20 placebo-controlled trials recruiting over 20,000 patients have demonstrated the benefit of long-term $\beta$-blockers in improving symptoms and quality of life in HF patients as well as reducing mortality and the frequency of hospitalization.

In most of these trials, the administered doses of $\beta$-blockers were either based on a pre-set minimum cutoff value for systolic blood pressure or clinical evidence of maximum benefit, regardless of the resultant minimum systolic blood pressure (Table 1). Evidence suggests that the favorable response to $\beta$-blockers in HF patients is dose dependent. In the Multicenter Oral Carvedilol HF Assessment (MOCHA) trial, Bristow et $\mathrm{al}^{15}$ described a dosedependant effect of carvedilol on 6-month mortality in patients with mild to moderate HF (Figure 1). Similar dose-related positive effects were seen on left ventricular ejection fraction (LVEF) as well as cardiovascular rehospitalization. 
Table 1. Initiation, target and mean doses of various $\beta$-blockers in major trials

\begin{tabular}{lllc}
\hline Study (investigation drug) & Initiation dose & Target dose & Mean dose (mg/day) \\
\hline CIBIS I (bisoprolol) $^{11}$ & $1.25 \mathrm{mg}$ daily & $5 \mathrm{mg}$ daily & 3.8 \\
US CHFS (carvedilol) $^{6}$ & $6.25 \mathrm{mg} \mathrm{BID}$ & $25-50 \mathrm{mg}$ BID & 45 \\
CIBIS II (bisoprolol) $^{7}$ & $1.25 \mathrm{mg}$ daily & $10 \mathrm{mg}$ daily & 8.5 \\
MERIT -HF (metoprolol CR/XL) $^{8}$ & $12.5-25 \mathrm{mg}$ daily & $200 \mathrm{mg}$ daily & 159 \\
MDC (metoprolol) $^{12}$ & $5 \mathrm{mg} \mathrm{BID}$ & $75 \mathrm{mg} \mathrm{BID}$ & 108 \\
CAPRICORN (carvedilol) $^{13}$ & $6.25 \mathrm{mg} \mathrm{BID}$ & $25 \mathrm{mg} \mathrm{BID}$ & 44 \\
COPERNICUS (carvedilol) $^{14}$ & $3.125 \mathrm{mg} \mathrm{BID}$ & $25 \mathrm{mg} \mathrm{BID}$ & 37
\end{tabular}

CIBIS, The Cardiac Insufficiency Bisoprolol Study; US CHFS, US Carvedilol Heart Failure Study; MERIT-HF, Metoprolol CR/XL Randomized Intervention trial in Congestive Heart Failure; MDC, Metoprolol in Dilated Cardiomyopathy trial; CAPRICORN, the Carvedilol Post-Infarct Survival Control in LV Dysfunction trial; COPERNICUS, the Carvedilol Prospective Randomized Cumulative Survival study; BID, twice daily.

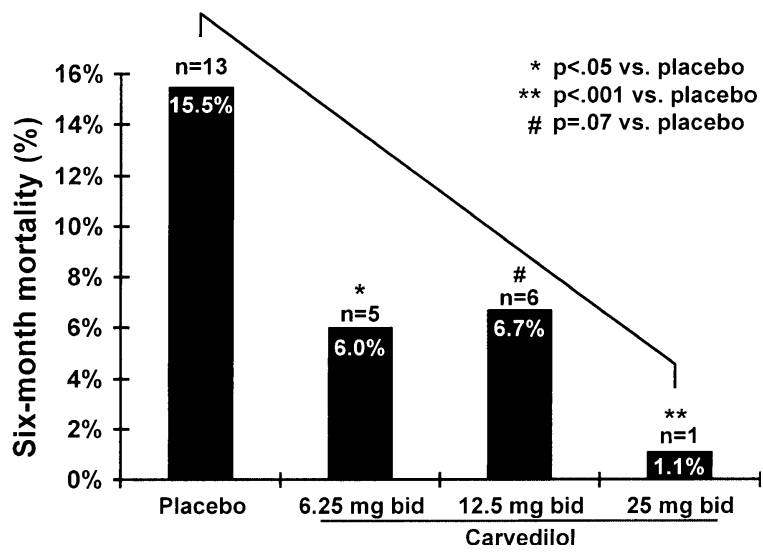

Figure 1. Six-month mortality among HF patients receiving placebo and incremental doses of carvedilol (Bristow et al. ${ }^{15}$ ). Used with permission from Circulation.

\section{TARGET DOSES OF ACE-INHIBITORS AND ANGIOTENSIN RECEPTOR BLOCKERS}

Pharmacologic inhibition of the renin-angiotensin system can be achieved via inhibition of conversion of angiotensin I to angiotensin II (ACE-inhibitors) or blockade of angiotensin receptors (ARBs). A meta-analysis of randomized, placebo-controlled trials, assessing over 7,000 patients with varying degrees of left ventricular (LV) dysfunction, showed improvement in cardiovascular outcome and mortality with the use of ACEinhibitors. ${ }^{16}$ However, patients with low blood pressure ( $<90 \mathrm{~mm} \mathrm{Hg}$ systolic) and/or impaired renal function (serum creatinine $>2.5 \mathrm{mg} / \mathrm{mL}$ ) were commonly excluded from these studies. ${ }^{17-22}$

What are the target doses (Table 2) of ACE-inhibitors in treating HF? In most clinical trials studying ACEinhibitors, the dose was not determined by a patient's therapeutic response but was increased until a pre-set target dose was reached. ${ }^{21,22,27}$ In clinical practice, however, these drugs are often prescribed at lower than recommended maintenance doses. In the Assessment of Treatment with Lisinopril and Survival (ATLAS) trial, ${ }^{28}$ which is one of the few major studies comparing the effect of low and high doses of ACE-inhibitors on clinical outcome, a non-significant improvement in mortality but a significant decrease in hospitalization for worsening HF $(P=.002)$ as well as improvement in combined end point of death or hospitalization $(P=.002)$ was noted in the high-dose lisinopril group compared to the low-dose group. In another major trial, NETWORK, ${ }^{29}$ low, medium, and high doses of enalapril showed similar effects on a combination of death, HF-related hospitalizations, and worsening HF symptoms as the primary endpoint. Other studies have compared low- and high-dose ACE-inhibitors but are substantially limited compared to ATLAS and NETWORK in terms of statistical power to assess mortality and outcome. ${ }^{30-32}$ Overall, these trials demonstrate a potential advantage of higher doses in terms of improved symptoms and reduced frequency of hospitalizations, but do not provide conclusive proof that higher doses improve survival. These results may have led to less aggressive recommendations and guidelines regarding titration of ACE-inhibitors and ARBs in HF patients as compared to $\beta$-blockers. ${ }^{33}$ As for ARBs, the candesartan in HF: Assessment of Reduction in Mortality and Morbidity (CHARM) study reported significant but similar improvement in outcome with low, medium, and high doses of candesartan. ${ }^{26}$

From these and other studies, it is apparent that $\beta$-blockers, ACE-inhibitors, and ARBs have provided substantial benefits for HF patients in clinical trials. It is not clear that the full benefits of these agents are provided when they are used in reduced doses compared to the doses used in the major clinical trials. In a study of HF subjects treated in an outpatient setting, PetersKlimm et $\mathrm{al}^{34}$ found that $75 \%$ of patients received $\beta$-blockers and $80 \%$ received an ACE-inhibitor or ARB. 
Table 2. Initiation, target and mean doses of various ACE-inhibitors and ARBs in major trials

\begin{tabular}{|c|c|c|c|}
\hline Study (investigation drug) & Initiation dose & Target dose & Mean dose (mg/day) \\
\hline SAVE (captopril) ${ }^{23}$ & $12.5 \mathrm{mg}$ TID & $50 \mathrm{mg}$ TID & N/A \\
\hline CONSENSUS (enalapril) ${ }^{22}$ & 2.5 mg daily & 40 mg daily & 18 \\
\hline SOLVD Prevention (enalapril) ${ }^{24}$ & $2.5 \mathrm{mg}$ daily & 20 mg daily & 16 \\
\hline SOLVD Treatment (enalapril) ${ }^{21}$ & 2.5 mg daily & 20 mg daily & 11 \\
\hline AIRE (ramipril) ${ }^{25}$ & $2.5 \mathrm{mg}$ BID & 5 mg BID & $\mathrm{N} / \mathrm{A}$ \\
\hline CHARM (candesartan) ${ }^{26}$ & 4 mg daily & 32 mg daily & $\mathrm{N} / \mathrm{A}$ \\
\hline
\end{tabular}

SAVE, The Survival and Ventricular Enlargement trial; CONSENSUS, the Cooperative North Scandinavian Enalapril Survival Study; SOLVD, Studies of Left Ventricular Dysfunction; AIRE, the Acute Infarction Ramipril Efficacy study; CHARM, the Candesartan in Heart Failure: Assessment of Reduction in Mortality and Morbidity program.

Nevertheless, adherence to guideline recommendations for target therapeutic dose was only accomplished in $8 \%$ of patients for $\beta$-blockers and $16 \%$ for an ACE-inhibitor or ARB. Even with adjustment for contraindications for drug therapy, including chronic obstructive lung disease, hypotension, hyperkalemia, and renal dysfunction, only $46 \%$ of HF patients received $\beta$-blockers and $49 \%$ received ACE-inhibitors or ARBs in the targeted doses. Thus, inadequate HF drug dosing may be a common problem faced when trying to optimize HF therapy. This suggests a potentially important role for testing that could provide a metric to determine which drug is the most important to maximize in the patient with low baseline systolic blood pressure and what level of blood pressure lowering provides benefit, whereas further blood pressure lowering may be detrimental. Imaging the response of cardiac sympathetic nerve function to therapy may provide this type of metric.

\section{I-123 MIBG UPTAKE IN HF PATIENTS REFLECTS CARDIAC SYMPATHETIC NERVE ACTIVITY AND IMPROVES FOLLOWING TREATMENT WITH $\beta$-BLOCKERS, ACE-INHIBITORS, AND ALDOSTERONE INHIBITORS}

\section{Background of I-123 MIBG-Based Imaging}

Sustained hyperactivity of the cardiac sympathetic nervous system observed in $\mathrm{HF}$ is a consequence of increased central sympathetic outflow, altered neuronal norepinephrine (NE) reuptake, and facilitation of cardiovascular response to sympathetic stimulation by angiotensin II. Myocardial beta-adrenoceptor density is reduced in patients with HF. With progressive HF, there is reduced uptake of NE into presynaptic cardiac nerve storage vesicles via the NE uptake-1 transporter. Chronic over-exposure of post-synaptic beta-adrenergic receptors on the cardiomyocyte to $\mathrm{NE}$ in the synaptic cleft results in beta-receptor desensitization and eventual catabolism and loss of beta-receptors.

I-123 MIBG is the most widely used imaging agent for studying cardiac sympathetic hyperactivity. Uptake of I-123 MIBG into presynaptic sympathetic neurons occurs through the same uptake-1 transporter mechanism responsible for the reuptake of NE. Reduced function of the uptake-1 mechanism may lead to abnormally high levels of catecholamine in the synaptic cleft.

After intravenous injection of I-123 MIBG, early (20 minutes) and late (4 hours) planar and SPECT images are obtained. ${ }^{35}$ In addition to visual analysis of the images, a heart-to-mediastinum ratio (HMR) can be calculated as shown in Figure 2. The I-123 MIBG washout (WO) rate from the myocardium can be calculated using early and delayed images. The effective dose resulting from an administered activity of $10 \mathrm{MCi}$ $(370 \mathrm{MBq}$ ) is $4.8 \mathrm{mSv}$, so the activity from serial doses is consistent with dosing from a single rest/stress Tc$99 \mathrm{~m}$ myocardial perfusion scan.

\section{Imaging of Cardiac Adrenergic Activity as Predictor of Outcome}

Many studies have demonstrated that impaired cardiac adrenergic innervation assessed by I-123 MIBG imaging is strongly related to adverse cardiac events and mortality in patients with HF. ${ }^{36}$ The AdreView Myocardial Imaging for Risk Evaluation in HF (ADMIRE-HF) trial $^{37}$ evaluated $961 \mathrm{HF}$ patients (NYHA class II-III, LVEF < 35), using a prospectively selected HMR of 1.6 to separate low- from high-risk patients. The combined adverse event rate was found to be $15 \%$ for patients with an HMR $\geq 1.6$ and $37 \%$ for HMR $<1.6$ (hazard ratio [HR] $0.40, P<.001)$. A late HMR $\geq 1.6$ was independently associated with a reduced risk for $\mathrm{HF}$ progression (HR 0.49, $P=.002)$, cardiac death (HR $0.14, P=.006$ ), 

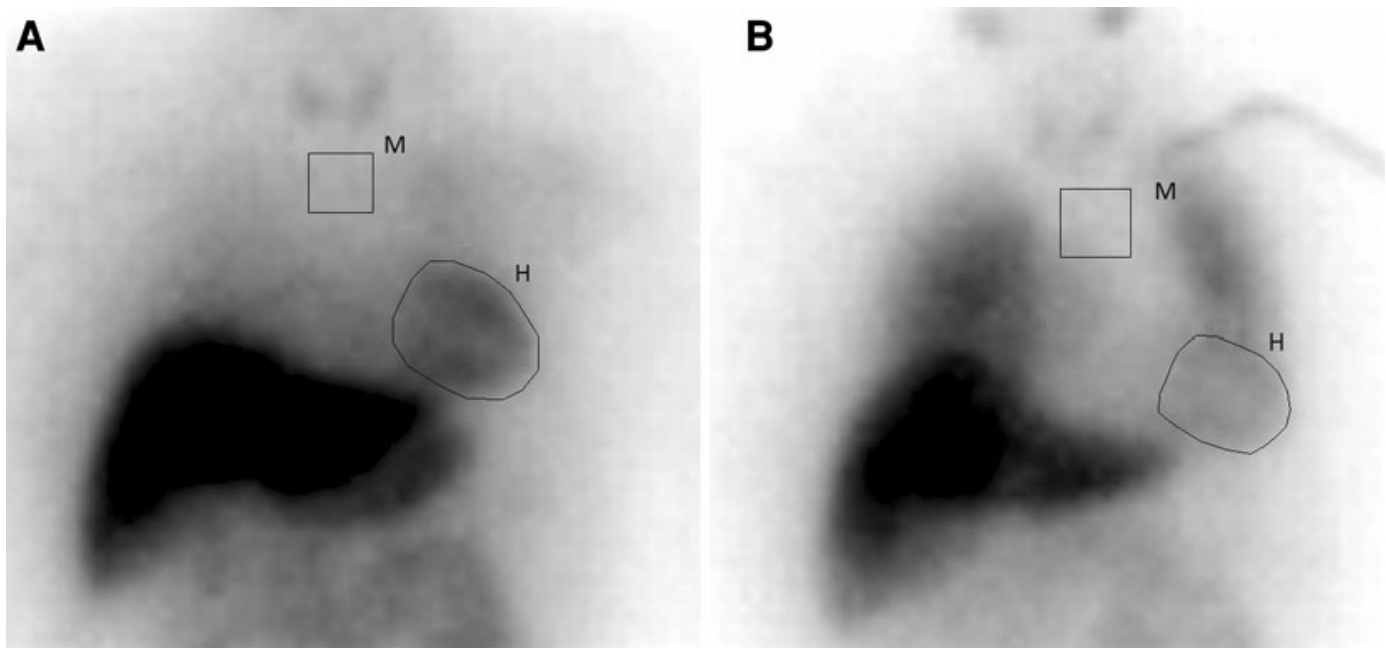

Figure 2. Normal (A) and reduced (B) heart-to-mediastinum ratio (HMR).

and potentially life-threatening arrhythmic events (HR $0.37, P=0.02$ ).

\section{Cardiac I-123 MIBG Imaging in Predicting Effect of Medical Therapy}

As clinical status and LV function improve in response to $\beta$-blockers, ACE-inhibitors, ARBs, and/or aldosterone antagonists, there is a parallel improvement in cardiac sympathetic nerve function as assessed by I- 123 MIBG. In 30 NYHA class II or III HF patients treated with $16 \pm 4 \mathrm{mg} /$ day of carvedilol for $12 \pm 1$ months, Kasama et al. ${ }^{38}$ noted that an improvement from baseline in B-type natriuretic peptide from $270 \pm 249$ to $148 \pm 125(P=$ $.002)$ and in LVEF from $33 \pm 6$ to $39 \pm 6(P=.003)$ was paralleled by an improvement in late I-123 MIBG HMR from $1.66 \pm 0.16$ to $1.88 \pm 0.23(P<.001)$. Similar concordant improvement in cardiac sympathetic nerve function with improvement in clinical status and/or LVEF has also been observed in response to treatment with metoprolol, ${ }^{39}$ carvedilol, ${ }^{40,41}$ bisoprolol, ${ }^{42}$ enalapril, ${ }^{43}$ candesartan, ${ }^{44}$ and spironolactone. ${ }^{45}$

Improvement in LVEF in response to $\beta$-blocker therapy has been documented in HF patients with a broad range of baseline sympathetic neural impairment. ${ }^{46}$ For an individual HF patient, the cardiac sympathetic neural response to drug intervention may provide insight into the amount of benefit provided compared to other HF treatments. Neural imaging studies may have a role in differentiating patients likely to benefit from medical therapy from those that are likely to show poor long-term response and thus might be better candidates for nonmedical therapy (e.g., device therapy and cardiac transplantation). Furthermore, neural imaging may help identify patients in whom aggressively increasing medical therapy, despite mild hypotension or other mild side effects, might produce a more favorable clinical outcome.

\section{WHAT IS THE LOWER LIMIT OF SYSTEMIC BLOOD PRESSURE THAT SHOULD BE TARGETED WITH $\beta$-BLOCKERS, ACE-INHIBITORS, AND ANGIOTENSIN RECEPTOR BLOCKERS?}

The majority of HF trials have used arbitrary lower limits of systemic blood pressure (e.g., $85-100 \mathrm{~mm} \mathrm{Hg}$ ) to determine the target therapeutic dose, without clear evidence of poorer outcome at lower systolic blood pressures. On the other hand, evidence of worsened outcome with or without treatment in HF patients with low systolic blood pressure has been well established. ${ }^{47}$

Because adrenergic stimulation plays an important role in maintaining both blood pressure and cardiac contractility in patients with impaired LV systolic function, the administration of adrenergic blocking drugs can cause both hypotension and worsening HF. The risk of these adverse circulatory reactions is most marked in patients with the lowest BP or most advanced disease before treatment. ${ }^{48}$ Such patients have generally responded poorly to treatment and have frequently been excluded from participation in clinical studies using beta-blocking drugs. ${ }^{7,8}$ An important exception is the Carvedilol Prospective Randomized Cumulative Survival (COPERNICUS) study $^{9,14}$ that evaluated the effects of carvedilol in patients with severe HF, including those with a very low SBP $(85-100 \mathrm{~mm} \mathrm{Hg})$. This study demonstrated a reduction in the risk of death $(P=.0014)$ and combined risk of death or hospitalization $(P<.001)$ in these patients using carvedilol, but did not explore whether pretreatment BP influenced the presence or magnitude of these benefits. A follow-up 
study by Rouleau et al. ${ }^{47}$ confirmed that progressively lower systolic blood pressure is associated with progressively worse outcomes. Nevertheless, $\beta$-blocker therapy improved outcome significantly for patients across the range of baseline systolic blood pressures. The benefits of beta-blockade appeared to be the greatest in the patients with chronic stable HF with the lowest baseline blood pressure. Baseline systolic BP does not appear to be a determinant of the response to ACEinhibitors $^{16}$ or ARB's in large-scale trials. In the CHARM study, similar improvement in outcome with low, medium, and high doses of candesartan was observed regardless of baseline systolic blood pressure. $^{26}$

\section{BY ASSESSING IMPACT ON SYMPATHETIC NERVOUS SYSTEM FUNCTION AS ASSESSED BY I-123 MIBG IMAGING, CAN AN OPTIMAL TARGET SYSTEMIC BLOOD PRESSURE BE IDENTIFIED FOR $\beta$-BLOCKER, ACE-INHIBITOR, AND ALDOSTERONE ANTAGONIST THERAPIES?}

The benefits of therapies that ameliorate the effects of neurohormonal imbalance in the failing heart are well established. For patients who respond well to HF therapy with full therapeutic doses of $\beta$ blockers, ACE-inhibitors or ARBs, and aldosterone antagonists, there is currently no potential advantage to an addition of neural imaging to monitor the response to proven therapy. Yet, it is clear that a significant proportion of $\mathrm{HF}$ patients are not receiving full, proven-to-be-effective doses of these HF drugs due to concerns about resultant hypotension. Although it is known that low baseline systolic blood pressure portends an adverse prognosis in HF patients, it is not clear to what extent doses of proven HF drugs should be up-titrated to improve prognosis in these patients. In the patient with a baseline systolic blood pressure of $95 \mathrm{~mm} \mathrm{Hg}$, does the outcome improve or worsen when a $\beta$-blocker, ACE-inhibitor, or ARB is increased and the blood pressure falls to $85 \mathrm{~mm} \mathrm{Hg}$ ? The symptomatic response of the patient may determine the treatment endpoint in some patients, but in patients who remain asymptomatic or minimally symptomatic, the blood pressure endpoint on treatment is often undefined. Does cardiac sympathetic innervation and activity improve or worsen as HF drug therapy is maximized to relatively low (e.g., $<90 \mathrm{~mm} \mathrm{Hg}$ ) systolic blood pressure levels? By identifying the target blood pressure that maximizes sympathetic nerve function, can HF outcome in response to medical therapy be optimized?

\section{Alternative Methods for Assessment of Cardiac Sympathetic Neuronal Function in HF Patients}

Elevated plasma norepinephrine levels are associated with increased sympathetic nervous system function and unfavorable outcomes in HF patients. ${ }^{49}$ Serial measurements might provide a method for assessing the response of the sympathetic nervous system to selection and dosing of HF medications, but have not entered into wide clinical use. Plasma norepinephrine levels are altered by a wide variety of physical and emotional stimuli that affect norepinephrine release, as well as changes in cardiac output and regional blood flow that vary the rate of removal of norepinephrine from the plasma. ${ }^{50}$ Heart rate variability is an indirect method for assessing cardiac sympathetic nerve activity and has been associated with HF outcomes in several studies. ${ }^{51}$ Reduced heart rate variability reflects sympathetic autonomic activity, but is also influenced by parasympathetic tone, chemoreceptor function, respiratory rate and tidal volume, mechanical factors (e.g., stretch of the atria from changes in cardiac filling and thoracic pressure), and level of physical activity. These multiple variables affecting heart rate variability, as well as the technical limitations in heart rate variability measurement, limit its potential to detect changes in cardiac sympathetic activity that may alter response to adjustment of medical therapy. ${ }^{52,53}$ In studies directly comparing heart rate variability to I-123 MIBG imaging, I-123 MIBG imaging was predictive of all-cause mortality ${ }^{54}$ and for either cardiac death or hospitalization for $\mathrm{HF},{ }^{55}$ whereas heart rate variability was not.

Cardiopulmonary exercise testing, with measurement of maximum oxygen consumption $\left(\mathrm{VO}_{2} \max \right)$, and the 6-minute walk do not focus specifically on cardiac sympathetic neuronal activity, but are well-validated and accepted procedures for measuring the functional response to HF treatment. These tests are important comparators for future studies to assess a potential role of serial neuronal imaging in the assessment of clinical response to modifications in HF therapy.

\section{WHAT IS NEEDED TO VALIDATE A MEANINGFUL ROLE OF CARDIAC NEURONAL IMAGING IN THE SELECTION OF MEDICAL THERAPY AND OPTIMAL THERAPEUTIC DOSES IN HF PATIENTS?}

(1) It must be determined if the reproducibility of the I-123 MIBG HMR measurement is adequate to accurately identify a significant change in response to a selection of medication or dose adjustment. The 
HMR is highly reproducible in normal subjects, ${ }^{56}$ however, HF subjects have low I-123 MIBG cardiac count statistics and HMR reproducibility is not well established. Nevertheless, the studies cited earlier show an increase in HMR in response to known effective HF drugs, indicating that improvement in neural function by HMR is measureable with I-123 MIBG. Whether these demonstrable changes in HMR reported in populations of HF patients will be paralleled by demonstrable changes in HMR in response drug dose changes in individual HF patients remains to be proven.

(2) The hypothesis requires testing that I-123 MIBG can identify differences in neuronal function in HF patients treated to moderate treatment goals (e.g., systolic blood pressure 95-105 mm Hg with no symptoms) versus aggressive goals (e.g., systolic blood pressure $85-95 \mathrm{~mm} \mathrm{Hg}$ and/or mild symptoms).

(3) The hypothesis also requires testing that patients with LVEF $\leq 35 \%$ and NYHA class II or III HF randomized to I-123 MIBG guided medical treatment have improved survival compared to patients treated by guidelines-based conventional HF treatment alone.

(4) Similarly, testing is needed to determine if severe HF patients with a poor versus favorable neuronal response to maximal medical therapy have a more favorable outcome with left ventricular assist devices compared to continued medical therapy alone.

With the growing burden of HF in our society, improving outcomes by optimizing HF medical therapy is a priority, and measuring the response of the cardiac sympathetic nervous system to treatment may help provide answers to difficult therapeutic questions.

\section{References}

1. Lloyd-Jones D, Adams R, Carnethon M, De Simone G, Ferguson TB, Flegal K, et al. Heart disease and stroke statistics-2009 update: A report from the American Heart Association Statistics Committee and Stroke Statistics Subcommittee. Circulation 2009;119:480-6.

2. Ungerer M, Böhm M, Elce JS, Erdmann E, Lohse MJ. Altered expression of beta-adrenergic receptor kinase and beta 1-adrenergic receptors in the failing human heart. Circulation 1993;87: 454-63.

3. Gerson MC, Abdallah M, Muth JN, Costea AI. Will imaging assist in the selection of patients with heart failure for an ICD? JACC Cardiovasc Imaging 2010;3:101-10.

4. Feldman DS, Carnes CA, Abraham WT, Bristow MR. Mechanisms of disease: Beta-adrenergic receptors-alterations in signal transduction and pharmacogenomics in heart failure. Nat Clin Pract Cardiovasc Med 2005;2:475-83.

5. Goldhammer E, Maor I, Shnitzer S, Lanir A, Abinader EG. The early anti-oxidant effect of carvedilol predicts the clinical course in congestive heart failure patients. J Cardiovasc Med (Hagerstown) 2007;8:453-6.

6. Packer M, Bristow MR, Cohn JN, Colucci WS, Fowler MB, Gilbert EM, et al. The effect of carvedilol on morbidity and mortality in patients with chronic heart failure. US Carvedilol Heart Failure Study Group. N Engl J Med 1996;334:1349-55.

7. CIBIS-II Investigators and Committees. The Cardiac Insufficiency Bisoprolol Study II (CIBIS-II): A randomised trial. Lancet 1999;353:9-13.

8. MERIT-HF Study Group. Effect of metoprolol CR/XL in chronic heart failure: Metoprolol CR/XL Randomised Intervention trial in Congestive Heart Failure (MERIT-HF). Lancet 1999;353:2001-7.

9. Packer M, Coats AJ, Fowler MB, Katus HA, Krum H, Mohacsi P, et al. Carvedilol Prospective Randomized Cumulative Survival Study Group. Effect of carvedilol on survival in severe chronic heart failure. N Engl J Med 2001;344:1651-8.

10. Hunt SA, Abraham W, Chin M, Feldman AM, Francis GS, Ganiats TG, et al. ACC/AHA 2005 Guideline update for the diagnosis and management of chronic heart failure in the adult. Circulation 2005;112:E154-235.

11. CIBIS Investigators and Committees. A randomized trial of betablockade in heart failure. The Cardiac Insufficiency Bisoprolol Study (CIBIS). Circulation 1994;90:1765-73.

12. Waagstein F, Bristow MR, Swedberg K, Camerini F, Fowler MB, Silver MA, et al. Beneficial effects of metoprolol in idiopathic dilated cardiomyopathy. Metoprolol in Dilated Cardiomyopathy (MDC) trial. Lancet 1993;342:1441-6.

13. Dargie HJ. Effect of carvedilol on outcome after myocardial infarction in patients with left-ventricular dysfunction: The CAPRICORN randomised trial. Lancet 2001;357:1385-90.

14. Packer M, Fowler MB, Roecker EB, Coats AJ, Katus HA, Krum $\mathrm{H}$, et al. Effect of carvedilol on the morbidity of patients with severe chronic heart failure: Results of the carvedilol prospective randomized cumulative survival (COPERNICUS) study. Circulation 2002;106:2194-9.

15. Bristow MR, Gilbert EM, Abraham WT, Adams KF, Fowler MB, Hershberger RE, et al. Carvedilol produces dose-related improvements in left ventricular function and survival in subjects with chronic heart failure. MOCHA Investigators. Circulation 1996;94:2807-16.

16. Garg R, Yusuf S. Overview of randomized trials of angiotensinconverting enzyme inhibitors on mortality and morbidity in patients with heart failure. Collaborative Group on ACE Inhibitor trials. JAMA 1995;273:1450-6.

17. Sharpe DN, Murphy J, Coxon R, Hannan SF. Enalapril in patients with chronic heart failure: A placebo-controlled, randomized, double-blind study. Circulation 1984;70:271-8.

18. Cleland JG, Dargie HJ, Hodsman GP, Ball SG, Robertson JI, Morton JJ, et al. Captopril in heart failure. A double blind controlled trial. Br Heart J 1984;52:530-5.

19. Bayliss J, Norell MS, Canepa-Anson R, Reid C, Poole-Wilson P, Sutton G. Clinical importance of the renin-angiotensin system in chronic heart failure: Double blind comparison of captopril and prazosin. Br Med J (Clin Res Ed) 1985;290:1861-5.

20. Drexler H, Banhardt U, Meinertz T, Wollschläger H, Lehmann M, Just H. Contrasting peripheral short-term and long-term effects of converting enzyme inhibition in patients with congestive heart failure. A double-blind, placebo-controlled trial. Circulation 1989;79:491-502.

21. The SOLVD Investigators. Effect of enalapril on survival in patients with reduced left ventricular ejection fractions and congestive heart failure. N Engl J Med 1991;325:293-302.

22. The CONSENSUS Trial Study Group. Effects of enalapril on mortality in severe congestive heart failure. Results of the 
Cooperative North Scandinavian Enalapril Survival Study (CONSENSUS). N Engl J Med 1987;316:1429-35.

23. Pfeffer MA, Braunwald E, Moyé LA, Basta L, Brown EJ Jr, Cuddy TE, et al. Effect of captopril on mortality and morbidity in patients with left ventricular dysfunction after myocardial infarction. Results of the survival and ventricular enlargement trial. The SAVE Investigators. N Engl J Med 1992;327:669-77.

24. The SOLVD Investigators. Effect of enalapril on mortality and the development of heart failure in asymptomatic patients with reduced left ventricular ejection fractions. N Engl J Med 1992; 327:685-91.

25. The Acute Infarction Ramipril Efficacy (AIRE) Study Investigators. Effect of ramipril on mortality and morbidity of survivors of acute myocardial infarction with clinical evidence of heart failure. Lancet 1993;342:821-8.

26. Meredith PA, Ostergren J, Anand I, Puu M, Solomon SD, Michelson EL, et al. Clinical outcomes according to baseline blood pressure in patients with a low ejection fraction in the CHARM (Candesartan in Heart Failure: Assessment of Reduction in Mortality and Morbidity) Program. J Am Coll Cardiol 2008; 52:2000-7.

27. Cohn JN, Johnson G, Ziesche S, Cobb F, Francis G, Tristani F, et al. A comparison of enalapril with hydralazine-isosorbide dinitrate in the treatment of chronic congestive heart failure. $\mathrm{N}$ Engl J Med 1991;325:303-10

28. Packer M, Poole-Wilson PA, Armstrong PW, Cleland JG, Horowitz JD, Massie BM, et al. Comparative effects of low and high doses of the angiotensin-converting enzyme inhibitor, lisinopril, on morbidity and mortality in chronic heart failure. ATLAS Study Group. Circulation 1999;100:2312-8.

29. The NETWORK Investigators. Clinical outcome with enalapril in symptomatic chronic heart failure; a dose comparison. Eur Heart J 1998;19:481-9.

30. Clement DL, De Buyzere M, Tomas M, Vanavermaete G. Longterm effects of clinical outcome with low and high dose in the Captopril in Heart Insufficient Patients Study (CHIPS). Acta Cardiol 2000;55:1-7.

31. Berger R, Kuchling G, Frey B, Kozanly I, Pacher R, Stanek B. ACE inhibitor dosage at the time of listing predicts survival. J Heart Lung Transplant 2000;19:127-33.

32. Nanas JN, Alexopoulos G, Anastasiou-Nana MI, Karidis K, Tirologos A, Zobolos S, et al. Outcome of patients with congestive heart failure treated with standard versus high doses of enalapril: A multicenter study. High Enalapril Dose Study Group. J Am Coll Cardiol 2000;36:2090-5.

33. Sharma D, Buyse M, Pitt B, Rucinska EJ. Meta-analysis of observed mortality data from all-controlled, double-blind, multiple-dose studies of losartan in heart failure. Losartan Heart Failure Mortality Meta-analysis Study Group. Am J Cardiol 2000;85:18792.

34. Peters-Klimm F, Müller-Tasch T, Schellberg D, Remppis A, Barth A, Holzapfel N, et al. Guideline adherence for pharmacotherapy of chronic systolic heart failure in general practice: A closer look on evidence-based therapy. Clin Res Cardiol 2008;97:244-52.

35. Carrió I, Cowie MR, Yamazaki J, Udelson J, Camici PG. Cardiac sympathetic imaging with mIBG in heart failure. JACC Cardiovasc Imaging 2010;3:92-100

36. Agostini D, Verberne HJ, Burchert W, Knuuti J, Povinec P, Sambuceti G, et al. I-123-mIBG myocardial imaging for assessment of risk for a major cardiac event in heart failure patients: Insights from a retrospective European multicenter study. Eur J Nucl Med Mol Imaging 2008;35:535-46.

37. Jacobson AF, Senior R, Cerqueira MD, Wong ND, Thomas GS, Lopez VA, et al. Myocardial iodine-123 meta-iodobenzylguanidine imaging and cardiac events in heart failure. Results of the prospective ADMIRE-HF (AdreView Myocardial Imaging for Risk Evaluation in Heart Failure) study. J Am Coll Cardiol 2010; 55:2212-21

38. Kasama S, Toyama T, Hatori T, Sumino H, Kumakura H, Takayama Y, et al. Evaluation of cardiac sympathetic nerve activity and left ventricular remodelling in patients with dilated cardiomyopathy on the treatment containing carvedilol. Eur Heart $\mathbf{J}$ 2007;28:989-95.

39. Fukuoka S, Hayashida K, Hirose Y, Shimotsu Y, Ishida Y, Kakuchi $\mathrm{H}$, et al. Use of iodine-123 metaiodobenzylguanidine myocardial imaging to predict the effectiveness of beta-blocker therapy in patients with dilated cardiomyopathy. Eur J Nucl Med 1997;24:523-9.

40. Agostini D, Belin A, Amar MH, Darlas Y, Hamon M, Grollier G, et al. Improvement of cardiac neuronal function after carvedilol treatment in dilated cardiomyopathy: A 123I-MIBG scintigraphic study. J Nucl Med 2000;41:845-51.

41. Cohen-Solal A, Rouzet F, Berdeaux A, Le Guludec D, Abergel E, Syrota A, et al. Effects of carvedilol on myocardial sympathetic innervation in patients with chronic heart failure. J Nucl Med 2005;46:1796-803.

42. Suwa M, Otake Y, Moriguchi A, Ito T, Hirota Y, Kawamura K, et al. Iodine-123 metaiodobenzylguanidine myocardial scintigraphy for prediction of response to beta-blocker therapy in patients with dilated cardiomyopathy. Am Heart J 1997;133:353-8.

43. Takeishi Y, Atsumi H, Fujiwara S, Takahashi K, Tomoike H. ACE inhibition reduces cardiac iodine-123-MIBG release in heart failure. J Nucl Med 1997;38:1085-9.

44. Kasama S, Toyama T, Kumakura H, Takayama Y, Ichikawa S, Suzuki T, et al. Effects of candesartan on cardiac sympathetic nerve activity in patients with congestive heart failure and preserved left ventricular ejection fraction. J Am Coll Cardiol 2005;45:661-7.

45. Kasama S, Toyama T, Kumakura H, Takayama Y, Ichikawa S, Suzuki T, et al. Effect of spironolactone on cardiac sympathetic nerve activity and left ventricular remodeling in patients with dilated cardiomyopathy. J Am Coll Cardiol 2003;41:574-81.

46. Gerson MC, Craft LL, McGuire N, Suresh DP, Abraham WT, Wagoner LE. Carvedilol improves left ventricular function in heart failure patients with idiopathic dilated cardiomyopathy and a wide range of sympathetic nervous system function as measured by iodine 123 metaiodobenzylguanidine. J Nucl Cardiol 2002;9:608-15.

47. Rouleau JL, Roecker EB, Tendera M, Mohacsi P, Krum H, Katus $\mathrm{HA}$, et al. Influence of pretreatment systolic blood pressure on the effect of carvedilol in patients with severe chronic heart failure: The Carvedilol Prospective Randomized Cumulative Survival (COPERNICUS) study. J Am Coll Cardiol 2004;43:1423-9.

48. Waagstein F, Caidahl K, Wallentin I, Bergh CH, Hjalmarson A. Long-term beta-blockade in dilated cardiomyopathy. Effects of short- and long-term metoprolol treatment followed by withdrawal and readministration of metoprolol. Circulation 1989;80:551-63.

49. Cohn JN, Levine TB, Olivari MT, Garberg V, Lura D, Francis GS, et al. Plasma norepinephrine as a guide to prognosis in patients with chronic congestive heart failure. N Engl J Med 1984;311:81923.

50. Esler M, Kaye D. Measurement of sympathetic nervous system activity in heart failure: The role of norepinephrine kinetics. Heart Fail Rev 2000;5:17-25.

51. Nolan J, Batlin PD, Andrews R, Lindsay SJ, Brooksby P, Mullen $\mathrm{M}$, et al. Prospective study of heart rate variability and mortality in chronic heart failure. Circulation 1998;98:1510-6.

52. Mortara A, Sleight P, Pinna GD, Maestri R, Prpa A, La Rovere MT, et al. Abnormal awake respiratory patterns are common in 
chronic heart failure and may prevent evaluation of autonomic tone by measures of heart rate variability. Circulation 1997;96: 246-52.

53. Notarius CF, Floras JS. Limitations of the use of spectral analysis of heart rate variability for the estimation of cardiac sympathetic activity in heart failure. Europace 2001;3:29-38.

54. Anastasiou-Nana MI, Terrovitis JV, Athanasoulis A, Karaloizos L, Geramoutsos A, Pappa L, et al. Prognostic value of iodine-123metaiodobenzylguanidine myocardial uptake and heart rate variability in chronic congestive heart failure secondary to ischemic or idiopathic dilated cardiomyopathy. Am J Cardiol 2005;96:427-31.
55. Yamada T, Shimonagata T, Fukunami M, Kumagai K, Ogita H, Hirata A, et al. Comparison of the prognostic value of cardiac iodine-123 metaiodobenzylguanidine imaging and heart rate variability in patients with chronic heart failure: A prospective study. J Am Coll Cardiol 2003;41:231-8.

56. Somsen GA, Verberne HJ, Fleury E, Righetti A. Normal values and within-subject variability of cardiac I-123 MIBG scintigraphy in healthy individuals: Implications for clinical studies. J Nucl Cardiol 2004;11:126-33. 